J. Management and Humanity Research

Vol. 3, 2020, 43-59

ISSN: 2582-7766 (online)

Published on 15 July 2020

www.researchmathsci.org

DOI: http://dx.doi.org/10.22457/jmhr.v03a05105

Journal of

\title{
Research on the Impact of Alliance Portfolio Diversity on International Performance in Multinational Alliance
}

\author{
Zhi Liu \\ School of Economics and Management \\ Chongqing University of Posts and Telecommunications \\ Chongqing 400065, China. Email: liuz1223@163.com \\ Address: No.2 Chongwen Road, Nan'an District, Chongqing 400065, China
}

Received 1 June 2020; accepted 12 July 2020

\begin{abstract}
Alliance portfolio is an important means of enterprise internationalization, and diversity is an important factor that determines the value of alliance portfolio. However, there has been a lack of consensus on the composition of alliance portfolio diversity and its impact on international performance. Based on the integration of resource dependence theory and knowledge-based theory, this paper puts forward the two concepts of the functional diversity of the alliance portfolio and the diversity of the alliance structure, and constructs the influence path between the variables under the theoretical framework of the multinational alliance. Empirical testing with the help of sample enterprise data found that there is a significant positive relationship between the functional diversity of the alliance portfolio and the diversity of the alliance structure; there is a significant positive relationship between the functional diversity of the alliance portfolio and the international performance of the enterprise, where corporate status and uncertainty play positive and negative regulatory roles, respectively.
\end{abstract}

Keywords: functional diversity of alliance portfolio; diversity of alliance structure; corporate status; uncertainty

\section{Introduction}

An alliance is a cooperative model formed by multiple organizations with the purpose of achieving the strategic goals of sharing markets, resources and technologies, which is based on different agreements and contracts, has complementary or complementary, and shared risks advantages 1, formed alliance is a conventional means for enterprises to concentrate incompletely tradable resources, and then use existing resources and create new resources more efficiently 2 . However, duo to the limitation of the single alliance in integration effect and the fact that multiple alliances are simultaneously established and widely used in key industries such as computer software, electronics, pharmaceuticals, and air transportation in specific practice, the single alliance's inability to explain reality is exacerbated, making the strategy study of alliances has gradually shifted from the perspective of single alliances to the perspective of alliance combination, which has gradually replaced the position of single alliances in the field of strategic management research, and has become the focus of research by many scholars 3-. However, unlike the 


\section{Zhi Liu}

definition of alliance in the general sense, which has basically reached the consensus of scholars, there are different opinions on the definition of alliance combination, each insisting on explaining their own understanding from various angles $7,:$ From a perspective of cumulative integration, the alliance portfolio refers to the sum of all strategic alliances of the focus enterprise; from the learning perspective, the alliance combination is the sum of the experience of the focus enterprise alliance; from the multilateral alliance perspective, the alliance combination refers to the alliance group which is composed by the same goal and has at least two partners. However, although the definition of alliance portfolio based on the cumulative perspective has strong practicality and operability, it ignores the difference of alliance objects, that is, the possibility of the existence of repeated alliances with the same partner 6; Although the definition of alliance portfolio based on the learning perspective has transformed from a onedimensional measurement emphasizing the number of alliances into two-dimensional measurement combining the time and quantity dimensions, emphasizing the alternation, inheritance and aggregation of old and new alliances, it has enriched and expanded the definition and connotation of alliance portfolio., but it is easy to be confused with the concept of alliance experience itself, causing a certain degree of confusion; the definition of alliance portfolio based on the perspective of multilateral alliances, although to some extent responds to the criticism that traditional alliance portfolio lack of concern about the enterprise's overall formation of alliances, but at the same time introduced the phenomenon of ambiguity in the definition, measurement and quantification of the alliance group. Therefore, combining the above-mentioned advantages and criticisms of the definition of alliance portfolio from various angles and the specific reality of this paper, this article defines alliance combination as the sum of the number of alliances formed by multiple partners for the same goal.

Alliance portfolio is an important means of corporate internationalization 6 , and diversity has an important influence in the context of alliance portfolio 8. In today's complex and rapidly changing international market environment, the efforts that companies try to survive, consolidate and develop in the international market only by relying on their own meager power appear to be very insignificant and inoperable, and the diversity of alliance portfolios is very beneficial for enterprises to predict the future situation more accurately and use existing resources more efficiently and discover new resources in this highly uncertain environment9. Although the positive or negative relationship between the diversity of alliance portfolios and corporate performance has not yet reached a general consensus, studies have shown that there is an inverted Ushaped relationship between the diversity of alliance portfolios and corporate performance 10, and research has also emphasized, the diversity of alliance portfolio has a positive relationship with corporate performance 11 , but the importance of the diversity of alliance portfolio as a determinant of corporate survival has reached a certain extent 12.

Even so, this paper believes that there are still the following gaps on this issue: First, the existing research mainly treats the diversity of alliance portfolios as independent and complete variables, or step back to study its motivation or base itself to study its management methods or further study its impact on other factors such as performance, thus ignoring the richness and variability contained in the diversity of alliance portfolios, and lack of concern for its internal interconnection mechanism; second, As the 
Research on the Impact of Alliance Portfolio Diversity on International

Performance in Multinational Alliance

conventional transmission medium in the relationship between the diversity of alliance portfolios and performance, the alliance structure is generally divided into equity and non-equity forms, which ignores the diversity and complexity of the alliance structure itself, which limits the complex and changeable interaction between the alliance portfolio and the alliance structure.

In order to make up for the above research gaps, this paper combines the functional diversity of alliance portfolios and the diversity of the refined alliance structure under the resource-based view, integrates the knowledge-based theory and the related literature on resource dependence theory, and proposes the diversity of alliance's portfolio has a positive relationship with international performance a framework in the transnational alliances. The theoretical contribution of this research is mainly to dig out the diversity of alliance portfolio in terms of functions, and to further develop and refine the alliance structure on the basis of dividing the alliance structure into equity and non-equity. At the same time, it reveals the adjustment role the status of the enterprise and uncertainty in that two. and the positive relationship between the diversity of the alliance portfolio and the international performance, promote the consensus between the diversity of the alliance portfolio and the international performance, and it has great practical significance for today's manufacturing and high-tech industries in China, which try to achieve further internationalization, thereby enhancing international performance, and consolidating and developing its own industry position by adopting a transnational alliance.

\section{Theoretical background and literature review}

Resource dependence theory has become one of the most widely used theoretical perspectives in the field of strategic alliance research because of its good adaptability and explanatory ability in the nature and behavior of enterprises. In the aspect of enterprise nature, resource dependence theory emphasizes that enterprises are the aggregation of resources, and having valuable, scarce and irreplaceable resources can promote the construction of enterprise core competitiveness. In terms of industrial behavior, the resource dependence theory explains that the core motivation for enterprises to participate in or form alliances across organizational and industrial boundaries is to obtain valuable resources to overcome their own limitations and realize their own advantages [13]. The former emphasizes that resources are the essence of the enterprise from the perspective of the enterprise's own construction, while the latter explains the motivation of forming alliance from the perspective of the enterprise's behavior purpose. At least two dimensions of the application of resource dependence theory in alliance portfolio research are derived from this: first, the effect of the alliance portfolio that enterprises participate in or form to make up for their own lack of resources may be exactly what they expect, that is, through the construction of alliance portfolio, enterprises get complementary resources and realize the stability and growth of performance, as shown in the research, the performance of alliance combination with higher degree of resource complementarity is also better [14]. At the same time, the alliance relationship with resource complementarity can reduce the possibility of opportunism [15]; second, the resources obtained by the alliance combination may overlap with the resources owned by the enterprise itself to a certain extent, resulting in conflicts and contradictions beyond the expectation within the combination, From this 


\section{Zhi Liu}

dimension, some researches emphasize that alliance enterprises should work together to achieve the synergy within the portfolio and avoid the conflict within the portfolio, so as to prevent the phenomenon of negative correlation between the diversity of alliance portfolio and performance [7]. However, the relationship between the diversity of alliance portfolio and its performance presents an inverted U-shape or even a negative relationship, which shows that from the perspective of alliance portfolio, the resources provided by a single alliance do not exist in isolation, but interact with the resources provided by other alliances. At the same time, it is also conditional to realize the resource accumulation effect of alliance combination [13]. In order to alleviate and avoid the phenomenon of resource overlapping in alliance portfolio that negatively affects enterprise performance, further subdividing the diversity in alliance portfolio in areas such as governance, industry, country, technology and organization has become the choice of many scholars [8,10], and on this basis, further exploring the relationship between alliance portfolio diversity and performance [6,12]. The results show that: national diversity can promote the increase of enterprises' access to resources and the number of entering the market, so as to improve performance; technological diversity can enable enterprises to obtain complementary technologies to make up for their own shortcomings, so as to develop performance; organizational diversity can provide more diversified channels for enterprises to obtain resources, so as to improve performance. However, only in the field of diversity of fine processing, to explore its internal relationship with performance, ignoring the improper choice of alliance structure is also an important factor that leads to the failure of the alliance and thus affects the performance [4].

The necessity and urgency of bridging the gap between enterprises in terms of structure, culture and planning makes the partners of alliance not only have requirements in terms of technology and other resources, but also an important factor to consider in terms of knowledge absorption and internalization ability [16]. However, based on the resource dependence theory, it emphasizes that the enterprise is a collection of tangible and intangible knowledge, which only illustrates the static aspect of the essence of the enterprise and ignores the dynamic aspect that the enterprise should identify, select, develop and deploy resources to create excellent performance [17]. To a certain extent, the knowledge-based view is making up for the lack of dynamic characteristics of resource dependence theory. It holds that the knowledge owned by individuals and organizations is the basis of the company level, the source of competitive advantage, and the basic point of building enterprise capacity [18]. The correct selection and accurate judgment of alliance structure is not only an important performance of knowledge accumulation for efficient development and utilization of resources, but also an important way to avoid alliance failure and promote performance stability and growth, which is of great importance [4]. In the current research, the alliance structure is divided into equity and non-equity based on equity, which is the mainstream [19]. Equity alliance involves equity transfer or creation, mainly including direct equity investment and joint venture; non equity alliance does not involve any form of equity transfer, including various contract based on arrangements. However, this equity based on dichotomy of alliance structure into equity alliance and non-equity alliance is a little rough in explaining the flexible use of all knowledge to achieve performance growth, ignoring the huge possibility and diversity of the two, such as the applicability difference of non-equity 
Research on the Impact of Alliance Portfolio Diversity on International

Performance in Multinational Alliance

alliance structure in alliance types with different functions. Specifically, patent licensing or franchise will appear "acclimatized" in the alliance aiming at marketing function, so we should subdivide the alliance structure again on the basis of the above division, and put forward the diversity of alliance structure, so as to explore the possible interaction between the alliance with different functions, diversified alliance structure and performance, and promote the possibility of agreement in the relationship between alliance portfolio and performance in relevant research.

\section{Research hypothesis}

\subsection{The explanatory role of functional diversity of alliance portfolio}

There are numerous motivations or reasons for enterprises to participate in or form alliances, such as obtaining key complementary resources, reducing costs and risks, and enhancing the ability to resist crises 20 . In the specific practice and operation, it is a conventional choice for enterprises to set up or participate in functional alliances that adapt to their own circumstances and needs, such as information sharing, product design, technology research and development, production and marketing. At the same time, in order to ensure the smooth progress of cooperation and protect the common rights and interests of both sides in the process of alliance, it is a very operational way to formulate binding agreements or bring themselves into the interest sharing system. In this process, due to the significant differences between the alliance portfolio with different functions, it is very necessary and practical to adopt different ways of cooperation for different alliance types. Although some alliance structures have universal applicability, such as equity participation and joint venture, both of them can participate in the final benefit sharing process and avoid the collapse of cooperation or even legal disputes caused by unfair resource allocation or unfair income distribution in the alliance process, most of the non-equity cooperation modes are different between different functional alliances For example, patent authorization for technology $\mathrm{R} \& \mathrm{D}$ alliance is not suitable for intelligence sharing alliance, which is difficult to quantify. As the functional diversity of alliance combination increases, more and more detailed alliance structure is needed to match with it, so as to increase the diversity of alliance structure. Therefore, this paper assumes that

H1: the functional diversity of alliance portfolio has a positive impact on the diversity of alliance structure.

Alliances can serve different functional purposes. Enterprises can participate in or form functional alliances such as intelligence sharing, product design and marketing to expand their market coverage, enhance value creation and further develop their core competitiveness 21. For example, in the process of realizing and consolidating internationalization through transnational alliance, in order to reduce or avoid the possibility of decision-making mistakes caused by information asymmetry, product positioning dislocation caused by improper resource allocation, and excessive loss or even internationalization failure caused by market entry frustration, decision makers can choose to set up or participate in information sharing alliance to reduce the possibility of information asymmetry, and put forward suggestions that high frequency and intensity of information sharing can enhance the ability to resist crisis and risk, so as to increase the probability of smoothly entering and consolidating the international market and 


\section{Zhi Liu}

improving the international performance. At the same time, due to the great uncertainty contained in the external environment and the limitations of the enterprise's internal funds and resources, it is very impossible and unnecessary for the enterprise to try to own all the resources and capabilities of the whole process of product design, production and marketing independently in today's international market where the professional division of labor is so meticulous and popular, especially when the factors such as cultural environment, system and consumer preference may be significantly different from the local market, such efforts are more futile and inappropriate. Based on this situation, it is of great practical significance for enterprises to choose to participate in or establish multinational alliances with various functions in the process of internationalization, make up for their own shortcomings and defects, and enhance their resistance to uncertainty. When enterprises participate in more alliance functions, that is, the higher the functional diversity of alliance portfolio, the less short boards they have, the higher their ability to resist risks and crises, and the more likely they are to enter and consolidate the international market and improve their international performance. Therefore, this paper assumes that

$\mathrm{H} 2$ : the functional diversity of alliance portfolio has a positive impact on the internationalization performance of enterprises.

\subsection{The moderating role of enterprise status}

According to the resource dependence theory, the strategic positioning of an organization is related to the opportunity for the organization or decision-maker to access the required resources 22, that is, the decision-maker needs to take the resources he owns into consideration in the process of making strategic decisions, so that the strategic decisionmaking and positioning are limited by the resource space. Specifically, when the decision-maker can control or the enterprise has more resources, the decision-maker's autonomy and decision-making space will be greater in the process of strategic decisionmaking, and vice versa. The status of an enterprise represents the position of the enterprise in the local market, implies the discourse power of the enterprise in the industry, the influence on the market trend and direction, and even the strength of the connection with the government power. To a certain extent, it reflects and represents the number of resources accumulated and controlled by the enterprise, and determines the influence of the enterprise on itself in the process of international operation through transnational alliance. The position is high or low, which influences the judgment and choice of alliance structure. For example, when an enterprise has a higher position in the industry, it will have more resources to control and invest in the process of internationalization, so as to improve the market positioning of international products and give itself more space to choose the alliance structure, breaking through the limitation that enterprises with lower market position and less resources can only choose form of agreement on the basis of the diversified functions of the alliance portfolio23, we can choose the form of equity participation or joint venture that requires more resource base on the basis of contract, so as to increase the choice space of alliance structure and improve the diversity of alliance structure. So, we assume that

H3: in the relationship between the functional diversity of alliance portfolio and the diversity of alliance structure, enterprise status has a positive moderating effect. 
Research on the Impact of Alliance Portfolio Diversity on International

Performance in Multinational Alliance

\subsection{The moderating effect of uncertainty}

Environmental uncertainty refers to the unpredictability of changes in the organization's external environment, and this uncertainty is not a simple construct of a single dimension, but the result of the complex interaction of multiple dimensions, in which technological uncertainty and market uncertainty are its important components and manifestations 24 . This paper shapes and determines the degree of uncertainty from two dimensions of technology and market. In today's rapidly changing international market, uncertainty is an important factor for enterprises to carry out strategic alliance. It affects the difficulty of enterprises to obtain rich and accurate information from the environment, and then affects the decision-makers' judgment of product positioning and strategic choice. When the uncertainty is low, the relatively easy access to information gives decision-makers higher confidence and accuracy in predicting the market trend and future trend, which can give greater resource investment in the process of product internationalization, and has a greater tendency to choose the equity alliance structure with higher requirements for product positioning and capital investment, and has more choice space for alliance structure on the basis of contract form which judges the market trend and choosing with more caution and less resource demand, increasing the diversity of alliance structure. When the uncertainty is high, based on the transaction cost theory and resource dependence theory, the cooperation of multinational alliance has greater unpredictability, increases the transaction cost between partners, limits the decision-makers' imagination and self-confidence in product positioning and development, makes them more cautious in resource investment, and has a greater tendency to choose more conservative contract forms, so as to restrict the choice space of alliance structure and reduces the diversity of alliance structure. Therefore, this paper assumes that

H4: in the relationship between the functional diversity of alliance portfolio and the diversity of alliance structure, uncertainty has a negative moderating effect.

\subsection{The mediating role of alliance structural diversity}

According to behavioral decision-making theory, past performance is an important factor affecting decision-makers' judgment and cognition of the status quo, and the increase or decrease of performance has a profound impact on the choice and judgment of enterprises' internationalization strategy 25 . In the process of internationalization through transnational alliance, the behavior logic and inertia of enterprises, which were catalyzed and consolidated by high performance in the past, and in the process of collision with the local market in terms of environment, system and culture, often restrict the behavior of alliance partners according to the cooperation contract, ease the discomfort in the face of turbulent international market, so as to effectively avoid the operation of alliance to seek a new round of stability and growth of performance so as to verify the correctness of the previous behavior logic or to explore and improve the existing behavior. In order to make up for the lack of technology or resources in the whole process of product internationalization production and marketing, the alliance function that enterprises participate in or form has its corresponding functional characteristics and requirements. On the basis of the functional diversity of alliance portfolio, they choose the appropriate alliance structure to reduce the uncertainty and avoid risks to the greatest extent, and then 


\section{Zhi Liu}

improve the performance in line with the information processing theory, in this framework, due to the limitation of the enterprise's information processing ability, the behavior logic that has an impact on performance 26. In other words, although enterprises try to participate in or form various functional alliances to make up for their own shortcomings and defects in order to achieve the goal of international performance growth, in this process, enterprises also need to reach an alliance structure suitable for the functional alliance with alliance partners to restrict the behavior of partners, and strengthen the cooperative relationship with alliance partners to enhance their ability to resist unknown risks and uncertainties to achieve the effect of international growth. Therefore, this paper assumes that

H5: the diversity of alliance structure plays a mediating role in the relationship between the functional diversity of alliance portfolio and internationalization performance.

Based on the above literature review and analysis assumptions, this paper proposes a theoretical model as shown in Figure 1.

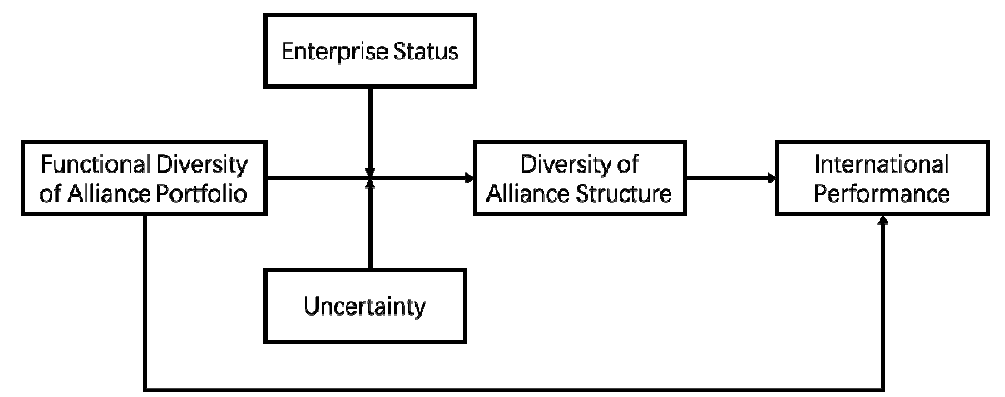

Figure 1: Theoretical model

\section{Research methods}

\subsection{Sample and data collection}

In the aspect of sampling design, this study combines stratified sampling and random sampling to make the sample evenly distributed and widely distributed. It focuses on manufacturing industry and high-tech represented by information technology. According to the definition of alliance portfolio, it brings the functional alliance directly constructed by the focus enterprises into the scope of alliance portfolio. In the aspect of data collection, this paper carries out the design of the scale according to the standardized process, and carries out the formal investigation by means of the electronic questionnaire based on the professional third platform, which is full of credibility and effectiveness. In 691 questionnaires, 512 questionnaires were collected, and the recovery rate was $74.10 \%$. Based on the foundation and framework of this study, in order to improve the preciseness of the research and the credibility of the conclusions, this study used the following methods to deal with the questionnaire: (1) to eliminate the questionnaire of domestic enterprises as the alliance objects in the process of internationalization; (2) When selecting the main or important partners of the specific alliance types (intelligence and information alliance, product design alliance, technology research and development alliance, production alliance and enterprise alliance)., the questionnaire of domestic 


\section{Research on the Impact of Alliance Portfolio Diversity on International}

Performance in Multinational Alliance

enterprises was selected to eliminate; (3) the questionnaire with incomplete or nonstandard answers was eliminated. After the above processing, 371 questionnaires were left, with an effective rate of $53.69 \%$. The basic characteristics of valid samples are shown in Table 1.

Table 1: Basic information of sample enterprises $(N=\mathbf{3 7 1})$

\begin{tabular}{llcc}
\hline Sample characteristics & \multicolumn{1}{c}{$\begin{array}{c}\text { Characteristic } \\
\text { distribution }\end{array}$} & Amount & $\begin{array}{c}\text { Percentage } \\
\text { Industry }\end{array}$ \\
& Manufacturing & 133 & 35.8 \\
& IT & 72 & 19.4 \\
& Wholesale and retail & 24 & 6.5 \\
& Other & 142 & 38.3 \\
Number of employees & $<100$ & 68 & 18.4 \\
& $101 \sim 500$ & 139 & 37.5 \\
& $501 \sim 1000$ & 83 & 22.4 \\
First internationalization & $>1000$ & 81 & 11.1 \\
time & Before 2000 & 41 & 11.1 \\
& $2000 \sim 2005$ & 57 & 15.4 \\
& $2005 \sim 2010$ & 83 & 22.4 \\
& $2010 \sim 2015$ & 108 & 29.1 \\
\hline
\end{tabular}

\subsection{Variable measurement}

(1) The functional diversity of alliance combination. The functional diversity of alliance portfolio is the independent variable of this study. This study refers to the general definition of alliance portfolio, through the enterprise in the alliance with different functions to choose different combinations to measure. Specifically, according to different functional characteristics, the alliance is divided into intelligence information alliance, product design alliance, technology $\mathrm{R} \& \mathrm{D}$ alliance, production alliance and marketing alliance. Based on the representative products with the best international performance or the widest international scope in the process of international operation, the enterprise selects the alliance types with different functional characteristics that are participated in or established in the process of internationalization, and takes the cumulative number selected from the above five alliance types as the final value of the variable. For example, if the representative products of an enterprise participate in or form information alliance and marketing alliance in the process of international operation, the value of functional diversity of the enterprise alliance combination is 2 .

(2) The diversity of alliance structure. The diversity of alliance structure is the mediating variable of this study. Referring to the research of Contractor and Lorange27, this paper further subdivides the alliance structure into technical training, patent authorization, joint research and development, joint laboratory, franchise, long-term supply agreement, channel use agreement, contract agreement (including production, assembly and repurchase agreement, management or marketing service agreement) and equity participation on the basis of equity and non-equity dichotomy. According to the characteristics of different alliance types, joint venture and other specific forms are reasonably allocated to each suitable alliance structure framework. Finally, the total sum of the above alliance structures involved in the five alliance types of representative products in the process of international operation is taken as the final value of the 


\section{Zhi Liu}

variable. For example, the representative products of an enterprise are involved in the form of patent licensing alliance of technology alliance, long-term supply agreement alliance structure of production alliance and joint venture alliance structure of marketing alliance in the process of international operation, and the diversity of alliance structure is 3.

(3) International performance. Internationalization performance is the dependent variable of this study. This paper refers to knight and Cavusgil's research 28, emphasizes that the internationalization performance of enterprises is represented by market increase and decrease and financial profit and loss, and forms a 6-item internationalization performance scale. All the measurement items adopt Likert 5-point scale, in which 1 stands for complete disagreement and 5 stands for complete agreement, requiring enterprises to objectively evaluate their internationalization performance in the international business process according to the actual situation. The specific measurement items are shown in Table 2.

(4) Enterprise status. Enterprise status is the moderator of this study. According to the theory of resource-based view, the amount of resources owned by enterprises often implies the level of discourse power of enterprises in the industry and the size of resource provision and control power in the alliance relationship, which means whether or not enterprises can occupy a dominant position in the alliance network. The status of an enterprise is a reflection of the amount of resources it has. In this study, the market share of the main products in the industry is used as the measurement dimension of enterprise status.

(5) Uncertainty. Uncertainty is the moderating variable of this study. Referring to hilmersson's research29, this paper uses eight items to measure the uncertainty faced by enterprises in the process of international operation in terms of market environment and technological change. All items use Likert's 5-point scale, in which 1 represents totally disagree and 5 represents totally agree. Respondents are required to objectively evaluate the uncertainty faced by enterprises in the process of international operation. The specific measurement items are shown in Table 2.

(6) Control variables. In order to test the specific effect of functional diversity of alliance portfolio on internationalization performance and the possible mediating effect of alliance structure diversity, this paper controls some enterprise level variables that may have a direct impact on internationalization performance. Studies have shown that 30 , different age of enterprises may lead to different organizational rigidity, which has a direct or indirect impact on internationalization performance. Therefore, this study uses the difference between the time of questionnaire collection and the time of establishment to express the age of enterprises. The complex rules and regulations that may be brought about by the increase of enterprise scale may reduce the flexibility and responsiveness of enterprises facing the ever-changing international market31, thus affecting the internationalization performance. Therefore, this paper uses different values to represent the number of employees in different ranges to express the enterprise scale. Understanding the moderating relationship is an important part of governance research 32. The experience accumulated in the long-term past international operation implied in the age of internationalization gives enterprises more learning opportunities and practical ability, which in turn affects the international performance. Therefore, this paper uses the difference between the time of questionnaire collection and the time of initial 


\section{Research on the Impact of Alliance Portfolio Diversity on International}

Performance in Multinational Alliance

internationalization to represent the age of internationalization. At the same time, for internationalized enterprises, the deepening of internationalization breadth often means that the market competition they are facing is further intensified 33 , so the internationalization performance fluctuates. Therefore, this paper uses different values to represent the quantity range of representative products of enterprises entering countries or regions, which represents the internationalization depth.

\subsection{Sample reliability and validity test}

Each variable and the specific measurement items of the variable, as well as the Cronbach's $\alpha$ value of the variable, the percentage that can explain of variance and the load value of each variable are shown in Table 2 . It can be seen from the table that the overall measurement scale has passed the Cronbach's $\alpha$ reliability test, the Cronbach's $\alpha$ coefficients of each factor are more than 0.6, all within the acceptable range; at the same time, the load value of each specific measurement item is more than 0.5 , showing good internal consistency; the percentage of variance can be explained is more than $50 \%$, showing a good degree of convergence.

Table 2: Reliability and convergent validity

\begin{tabular}{|c|c|c|c|c|}
\hline Variables & Variables measurement & Loading & Cronbach's $\alpha$ & $\begin{array}{l}\text { Explanatory } \\
\text { variance \% }\end{array}$ \\
\hline \multirow[t]{6}{*}{$\begin{array}{l}\text { International } \\
\text { performance }\end{array}$} & $\begin{array}{l}\text { The net profit in the international market } \\
\text { tends to increase }\end{array}$ & 0. & 0.634 & 65.120 \\
\hline & $\begin{array}{l}\text { The rate of return on investment in the } \\
\text { international market tends to increase }\end{array}$ & 0.754 & & \\
\hline & $\begin{array}{l}\text { Sales in the international market are } \\
\text { growing }\end{array}$ & 0.825 & & \\
\hline & $\begin{array}{l}\text { In the international market share continues } \\
\text { to expand }\end{array}$ & 0.598 & & \\
\hline & $\begin{array}{l}\text { Good customer satisfaction in the } \\
\text { international market }\end{array}$ & 0.714 & & \\
\hline & $\begin{array}{l}\text { Successful technical improvement and } \\
\text { upgrading in the international market }\end{array}$ & 0.831 & & \\
\hline \multirow[t]{8}{*}{ Uncertainty } & $\begin{array}{l}\text { There is uncertainty in the social system of } \\
\text { the international market }\end{array}$ & 0.848 & 0.705 & 61.087 \\
\hline & $\begin{array}{l}\text { It is difficult to predict the development } \\
\text { trend of technology and products }\end{array}$ & $0.65^{2}$ & & \\
\hline & $\begin{array}{l}\text { It is difficult to predict the potential market } \\
\text { capacity of products or services }\end{array}$ & 0.721 & & \\
\hline & $\begin{array}{l}\text { It is difficult to understand the potential } \\
\text { needs of customers }\end{array}$ & 0.791 & & \\
\hline & $\begin{array}{l}\text { The impact of government agencies on } \\
\text { business is uncertain }\end{array}$ & 0.755 & & \\
\hline & $\begin{array}{l}\text { The speed of technological change in the } \\
\text { industry is very fast }\end{array}$ & 0.851 & & \\
\hline & $\begin{array}{l}\text { It is difficult to predict the technological } \\
\text { competition in the industry }\end{array}$ & $0.8 c_{3} 3$ & & \\
\hline & $\begin{array}{l}\text { New product concept is difficult to imitate } \\
\text { and needs technical breakthrough }\end{array}$ & 0.737 & & \\
\hline
\end{tabular}




\section{Zhi Liu}

\section{Empirical analysis results}

\subsection{Descriptive statistics}

As shown in Table 3, the descriptive statistics show that there is a significant positive correlation between the independent variable, the functional diversity of alliance portfolio, the intermediary variable, the diversity of the alliance structure and the dependent variable, international performance. And the correlation coefficient between each variable is far below the critical value of 0.7. Although the correlation coefficient between the functional diversity of alliance portfolio and the diversity of alliance structure is 0.843 , which is higher than the critical value of 0.7 , the collinearity test shows that the variance expansion factor of the above two is 3.464, which is far lower than the critical value of 10 , so the collinearity problem between them is not serious. The above data and analysis show that further hypothesis testing can be carried out.

\begin{tabular}{|c|c|c|c|c|c|c|c|c|c|c|}
\hline Variables & Mean & ST.D & 1 & 2 & 3 & 4 & 5 & 6 & 7 & 8 \\
\hline 1.Firm age & 3.38 & 0.727 & & & & & & & & \\
\hline 2.Firm size & 3.42 & 1.130 & $.547^{* * *}$ & & & & & & & \\
\hline $\begin{array}{l}\text { 3.Age of } \\
\text { internationalization }\end{array}$ & 3.36 & 1.283 & $-420^{* *}$ & $\begin{array}{c}- \\
.375^{* *}\end{array}$ & & & & & & \\
\hline $\begin{array}{l}\text { 4. Breadth of } \\
\text { internationalization }\end{array}$ & 2.39 & 1.410 & $.274^{* *}$ & $.398^{* *}$ & $-\overline{403}^{\text {*** }}$ & & & & & \\
\hline 5.Firm status & 3.67 & 1.738 & .101 & $.202^{* *}$ & -.091 & $.156^{* *}$ & & & & \\
\hline 6.Uncertainty & 3.51 & 0.600 & .084 & .017 & .039 & .015 & -.020 & & & \\
\hline $\begin{array}{l}\text { 7.Functional } \\
\text { diversity of alliance } \\
\text { portfolio }\end{array}$ & 3.16 & 1.148 & $.134^{* *}$ & $.163^{* *}$ & $-.118^{*}$ & -.015 & $.135^{* *}$ & .001 & & \\
\hline $\begin{array}{l}\text { 8.Diversity of } \\
\text { alliance structure }\end{array}$ & 8.34 & 5.359 & .095 & $.183^{* *}$ & $-.122^{*}$ & .044 & $.219^{* *}$ & -.032 & $.843^{* * *}$ & \\
\hline $\begin{array}{l}\text { 9.International } \\
\text { performance }\end{array}$ & 4.04 & 0.488 & $.113^{*}$ & $.138^{* * *}$ & -.040 & .001 & .072 & $.226^{* *}$ & $.320^{* *}$ & $.268^{* *}$ \\
\hline
\end{tabular}

Table 3: Correlation coefficient of variables

Note: “*” is $p<0.050$, “**” is $p<0.010$, “***” is $p<0.001$.

\subsection{Hypothesis test}

In order to ensure the validity and consistency of the estimation and test of the model involved in this paper, before using the hierarchical regression method to verify the validity of the model and the correctness of the above assumptions, the effective sample data are processed as follows: (1) the explanatory variables and regulatory variables involved in the model are standardized; (2) the explanatory variables and control variables involved in the model are under variance expansion factor test which shows that the maximum variance expansion factor of the test variables is 1.638 , which is significantly lower than the critical value of 10 , indicating that there is no serious collinearity problem, and the next regression test can be carried out.

As shown in Table 4, model 1 includes all the control variables involved in this study. Based on Model 1, model 2 adds the independent variable, namely the functional diversity of alliance portfolio, and two regulatory variables, namely enterprise status and uncertainty, to explore the existence of the main effect. The regression results show that 
Research on the Impact of Alliance Portfolio Diversity on International Performance in Multinational Alliance

the functional diversity of alliance portfolio has a positive impact on the diversity of alliance structure and has statistical significance $(\beta=3.879, \rho<001)$, hypothesis 1 , that is, the functional diversity of alliance portfolio has a positive impact on the diversity of alliance structure, is supported. On the basis of the above, model 3 adds the interaction terms of regulatory variables, enterprise status and uncertainty, respectively, and the functional diversity of alliance portfolio verify the existence of regulatory effect. The regression results show that enterprise status has a significant positive moderating effect in the path of functional diversity of alliance portfolio and diversity of alliance structure ( $\beta=0.285, \rho<0.001$ ). Hypothesis 3 showing that enterprise status has a positive moderating effect in the relationship between functional diversity of alliance portfolio and diversity of alliance structure is supported. At the same time, uncertainty also has a significant negative moderating effect in this path $(\beta=-0.417, \rho<0.05)$. Hypothesis 4 , that is, in the relationship between the functional diversity of alliance portfolio and the structural diversity of alliance, the negative moderating effect of uncertainty is supported and verified.

Table 4: Regression analysis results

\begin{tabular}{|c|c|c|c|c|c|c|c|c|c|c|}
\hline \multirow{3}{*}{ Variable } & \multicolumn{6}{|c|}{ Diversity of alliance structure } & \multicolumn{4}{|c|}{ International performance } \\
\hline & \multicolumn{2}{|c|}{ Model 1} & \multicolumn{2}{|c|}{ Model 2} & \multicolumn{2}{|c|}{ Model 3} & \multicolumn{2}{|c|}{ Model 4} & \multicolumn{2}{|c|}{ Model 5} \\
\hline & Coefficient & $\rho$ & Coefficient & $\rho$ & Coefficient & $\rho$ & Coefficient & $\rho$ & Coefficient & $\rho$ \\
\hline \multicolumn{11}{|l|}{ control variable } \\
\hline Firm age & -0.219 & 0.641 & -0.462 & 0.068 & -0.356 & 0.151 & 0.032 & 0.436 & & \\
\hline Firm size & 0.900 & 0.004 & 0.211 & 0.206 & 0.187 & 0.250 & 0.038 & 0.164 & & \\
\hline International age & -0.364 & 0.148 & -0.038 & 0.776 & 0.073 & 0.585 & 0.014 & 0.512 & & \\
\hline $\begin{array}{l}\text { International breadth } \\
\text { Independent } \\
\text { variable }\end{array}$ & -0.224 & 0.314 & 0.140 & 0.244 & 0.198 & 0.093 & -0.009 & 0.634 & & \\
\hline $\begin{array}{l}\text { Functional diversity } \\
\text { of alliance portfolio }\end{array}$ & & & 3.879 & 0.000 & 4.274 & 0.000 & 0.129 & 0.000 & & \\
\hline \multicolumn{11}{|l|}{$\begin{array}{l}\text { Regulatory } \\
\text { variables }\end{array}$} \\
\hline Firm status & & & 0.299 & 0.001 & -0.604 & 0.016 & & & & \\
\hline uncertainty & & & -0.236 & 0.339 & 1.188 & 0.108 & & & & \\
\hline \multicolumn{11}{|l|}{ Interaction } \\
\hline $\begin{array}{c}\text { Functional } \\
\text { diversity } \times \text { firm status }\end{array}$ & & & & & 0.285 & 0.000 & & & & \\
\hline $\begin{array}{c}\text { Functional } \\
\text { diversityxuncertainty }\end{array}$ & & & & & -0.417 & 0.045 & & & & \\
\hline \multicolumn{11}{|l|}{ Mediating variables } \\
\hline $\begin{array}{l}\text { Diversity of alliance } \\
\text { structure }\end{array}$ & & & & & & & & & -0.002 & 0.953 \\
\hline $\mathrm{R}^{2}$ & 0.040 & & 0.728 & & 0.723 & & & & & \\
\hline$\Delta R^{2}$ & 0.040 & & 0.688 & & 0.737 & & & & & \\
\hline F & $3.089^{* * *}$ & & 305.845 & & 10.835 & & & & & \\
\hline
\end{tabular}




\section{Zhi Liu}

Model 4 includes control variables and independent variables. Different from model 2 , the dependent variable in model 4 is international performance. The regression results show that the functional diversity of alliance portfolio has a statistically significant effect on internationalization performance $(\beta=0.129, \rho<0.001)$. Hypothesis 2 , that is, the functional diversity of alliance portfolio has a positive impact on enterprise international performance, is verified.

Model 5 attempts to verify the mediating effect of the diversity of alliance structure between the functional diversity of alliance portfolio and the international performance. This study uses the "process", which is more convenient in SPSS, to test the mediating effect of the diversity of alliance structure. The regression results show that the mediating effect of the diversity of alliance structure on the functional diversity of alliance portfolio and the international performance of is not significant $(\beta=-0.002, \rho>0.05)$, so Hypothesis 5, that is, the mediating effect of the diversity of alliance structure on the influence of the functional diversity of alliance portfolio on the international performance has not been verified.

\section{Conclusion and discussion}

In the process of exploring the complex relationship between the functional diversity of alliance portfolio and the international performance of enterprises, based on the theoretical analysis and practical induction of previous studies, this paper puts forward the possibility that the functional diversity of alliance portfolio may be related to the diversity of alliance structure and international performance, and puts forward some factors of enterprises at their own level, for example, the enterprise status and external environment, such as uncertainty, may play a moderating role in this path, and the diversity of alliance structure itself plays a mediating role in this path. Finally, the above relationship is verified by the sample data of manufacturing industry and information technology industry. The empirical results show that the functional diversity of alliance portfolio has a significant positive effect on the diversity of alliance structure and internationalization performance, and enterprise status and uncertainty play a positive and negative moderating role in the relationship between the functional diversity of alliance portfolio and the diversity of alliance structure, respectively. However, the diversity of alliance portfolio tries to influence the diversity of alliance structure and then play a role in international performance, and the possibility of the transmission of the diversity of alliance structure is invalid.

The results of data analysis do not support the mediating role of the diversity of alliance structure in the functional diversity of alliance portfolio and international performance path. The reason may be that this paper involves the perfection of alliance structure and the rationality of the allocation of various specific alliance structures in the corresponding functional alliance types, that is, there may be incomplete examination in our existing framework of alliance structure due to the careless alliance structure, the data we collected is only a part of the actual situation, which has a certain locality. Or in the existing alliance structure, there is a certain degree of dislocation and deficiency in the process of matching and adapting to the corresponding functional alliance types, which limits the possibility that the enterprise representatives or managers can provide complete information and data. On the one hand, the possibility of such a problem is that in the process of China's deeper participation in the globalization process and the increasingly 
Research on the Impact of Alliance Portfolio Diversity on International

Performance in Multinational Alliance

mature market, the alliance structure presents a more diversified and complex situation, which makes the research lag and one-sided to a certain extent. On the other hand, it may be the cultural impact of cross-cultural and cross regional communication in the international alliance makes the thinking logic inertia formed in the long-term learning accumulation process of enterprises encounter difficulties in the collision with different cultures, which virtually increases the learning cost and leads to the incompleteness of understanding and practice of some alliance structures.

The practical implications of the research results are mainly reflected in the following three aspects.

First, the results show that in the context of transnational alliance, the functional diversity of alliance portfolio has a significant positive effect on international performance. Therefore, when enterprises choose to enter the international business by forming transnational alliances, they can consider increasing the functional diversity of alliance portfolio to a certain extent, so as to meet the diversified needs of enterprises due to lack of resources, information asymmetry and technical barriers in the process of internationalization, so as to improve the international performance of enterprises and promote the smooth entry of enterprises into the international market and develop steadily.

Second, in the process of increasing the functional diversity of alliance portfolio and pursuing the improvement of international performance, enterprises should avoid the dilemma of overestimating the market position of enterprises in the industry, resulting in the internationalization speed too fast and the lack of follow-up resources and funds supply. That is, enterprise managers should objectively evaluate the position of enterprises in the industry and make strategy of functional diversity of alliance portfolio combined based on it, and the corresponding alliance structure should be selected and determined according to local conditions. Specifically, when the status of enterprises is higher, the corresponding relationship between them should be strengthened; when the status of enterprises is lower, the corresponding relationship between them should be weakened.

Third, because the research results show that uncertainty has a significant negative moderating effect on the diversity of alliance structure in the functional diversity of alliance portfolio, managers can further realize that when selecting and judging the functional diversity of alliance portfolio, they should consider not only their own factors such as enterprise status, but also the external international environment of the enterprise. According to the degree of environmental uncertainty, carefully formulating the corresponding relationship between the functional diversity of alliance portfolio and the diversity of alliance structure. Specifically, when the uncertainty is low, the corresponding relationship between the two should be consolidated and strengthened, while when the uncertainty is high, the corresponding relationship between the two should be weakened.

\section{REFERENCES}

1. Y.P.Xie and J.Wang, Research on the impact of alliance relationship on innovation performance in the environment of technological uncertainty, Science of Science and Management of S.\& T, 38(05) (2017) 60-71(in Chinese). 


\section{Zhi Liu}

2. W.Mitchell, P.Dussauge and B.Garrette, Alliances with competitors: how to combine and protect key resources?, Creativity and innovation management, 11(3) (2002) 203-223.

3. D.Lavie, Alliance portfolios and firm performance: A study of value creation and appropriation in the US software industry, Strategic management journal, 28(12) (2007) 1187-1212.

4. P.Kale, J.H.Dyer and H.Singh, Alliance capability, stock market response, and longterm alliance success: the role of the alliance function, Strategic Management Journal, 23(8) (2002) 747-767.

5. W.H.Hoffmann, Strategies for managing a portfolio of alliances, Strategic Management Journal, 28(8) (2007) 827-856.

6. U.Wassmer, Alliance portfolios: A review and research agenda, Journal of Management, 36(1) (2010) 141-171.

7. W.H.Hoffmann, How to manage a portfolio of alliances, Long Range Planning, 38(2) (2005) 121-143.

8. W.Han and Y.Deng, Review and Prospect of alliance combination: interaction, dynamics and influence effects of alliance combination, Management Review, 30(10) (2018) 169-183(in Chinese).

9. S.E.Page, The Difference: How the Power of Diversity Creates Better Groups, Firms, Schools, and Societies-New Edition, Princeton University Press, 2008.

10. R.J.Jiang, Q.T.Tao and M.D.Santoro, Alliance portfolio diversity and firm performance, Strategic Management Journal, 31(10) (2010) 1136-1144.

11. G.Ahuja, Collaboration networks, structural holes, and innovation: A longitudinal study, Administrative Science Quarterly, 45(3) (2000) 425-455.

12. D.Lee, K.Kirkpatrick-Husk and R.Madhavan, Diversity in alliance portfolios and performance outcomes: A meta-analysis, Journal of Management, 43(5) (2017) 1472-1497.

13. Y.Deng and X.F.Huang, Promoting or avoiding competition: Research on the inverted U-shaped relationship between alliance portfolio partner competition and breakthrough innovation, Science of Science and Management of S.\& T, 38(10) (2017) 55-68 (in Chinese).

14. L.W.Li, Research on the antecedents and effects of complementary advantages of cooperation and alliance risk aversion, Science of Science and Management of S.\& T, 40(07) (2019) 75-87(in Chinese).

15. F.T.Rothaermel, Incumbent's advantage through exploiting complementary assets via interfirm cooperation, Strategic management journal, 22(6-7) (2001) 687-699.

16. J.Draulans, A.P.Deman and H.W.Volberda, Building alliance capability: Management techniques for superior alliance performance, Long Range Planning, 36(2) (2003) 151-166.

17. D.G.Sirmon, M.A.Hitt and R.D.Ireland, Managing firm resources in dynamic environments to create value: Looking inside the black box, Academy of Management Review, 32(1) (2007) 273-292.

18. R.M.Grant, Toward a knowledge - based theory of the firm, Strategic Management Journal, 17(S2) (1996) 109-122. 
Research on the Impact of Alliance Portfolio Diversity on International Performance in Multinational Alliance

19. M.Wright and A.Lockett, The structure and management of alliances: syndication in the venture capital industry, Journal of Management Studies, 40(8) (2003) 20732102.

20. J.Hagedoorn, Understanding the rationale of strategic technology partnering: Interorganizational modes of cooperation and sectoral differences, Strategic Management Journal, 14(5) (1993) 371-385.

21. C.K.Prahalad and G.Hamel, The core competence of the corporation, strategische unternehmungsführung. Springer, Berlin, Heidelberg, 2006, 275-292.

22. J.Pfeffer and G.R.Salancik, The external control of organizations: A resource dependence perspective, Stanford University Press, 2003.

23. X.Jiang, M.Li, and S.Gao, Managing knowledge leakage in strategic alliances: The effects of trust and formal contracts, Industrial Marketing Management, 42(6) (2013) 983-991.

24. X.Jiang and Y.Y.Ma, Environmental uncertainty, alliance green change and alliance performance, Management Review, 30(03) (2018) 60-71(in Chinese).

25. C.C.Markides, Diversification, restructuring and economic performance, Strategic Management Journal, 16(2) (1995) 101-118.

26. T.N.McGaffey and R.Christy, Information Processing Capability as a Predictor of Entrepreneurial Effectiveness, Academy of Management Journal, 18(4) (1975).

27. F.J.Contractor and P.Lorange, Why should firms cooperate? The strategy and economics basis for cooperative ventures, Cooperative Strategies in International Business, 1 (1988) 3-30.

28. G.Knight, and S.T.Cavusgil, Innovation, Organizational Capabilities, and the BornGlobal Firm, Journal of International Business Studies, 35(2) (2004) 124-141.

29. M.Hilmersson and H.Jansson, Reducing uncertainty in the emerging market entry process: on the relationship among international experiential knowledge, institutional distance, and uncertainty, Journal of International Marketing, 20(4) (2012) 96-110.

30. L.Naldi and P.Davidsson, Entrepreneurial growth: The role of international knowledge acquisition as moderated by firm age, Journal of Business Venturing, 29(5) (2014) 687-703.

31. Q.Xie, CEO tenure and ownership mode choice of Chinese firms: The moderating roles of managerial discretion, International Business Review, 23(5) (2014) 910-919.

32. F.Aime and D.K.Tarus, Board demographic diversity, firm performance and strategic change, Management Research Review, 37(12) (2015) 1110-1136.

33. J.L.Calof and W.Viviers, Internationalization behavior of small-and medium-sized South African enterprises, Journal of Small Business Management, 33(4) (1995) 71. 